\title{
Farklı Anaçlar Üzerine Aşılı Kokulu Kara Üzüm (Vitis labrusca L.) ve Şiraz (Vitis vinifera L.) Üzüm Çeşitlerinin Fidan Randımanı ve Gelişimi Üzerine Ağır Bünyeli Toprakların Etkileri
}

\author{
Bülent KÖSE ${ }^{1 *}$, Seda ATEŞ², Hüseyin ÇELiK² \\ ${ }^{1}$ Ondokuz Mayıs Üniv., Samsun Meslek Yüksekokulu, Bitkisel ve Hayvansal Üretim Programı, Samsun \\ ${ }^{2}$ Ondokuz Mayıs Üniversitesi, Ziraat Fakültesi, Bahçe Bitkileri Bölümü, Samsun \\ *Sorumlu Yazar: bulentk@omu.edu.tr
}

Öz

Bağ kurarken filoksera ile bulaşık alanlarda tek seçenek aşılı asma fidanı kullanmaktır. Yeni kurulacak bağlarda kullanılan aşıı asma fidanlarının iyi gelişmiş, sağlıklı ve çeşit/anaç kombinasyonunun iyi belirlenmiş olması gerekir. Aşılı asma fidanı üretiminde yüzdesel olarak I.Boy fidan üretimini en yüksek düzeyde tutmak en önemli hedeftir. Fidanlık toprağııın fidan randımanı ve kalitesi bakımından önemi çok fazladır. Bu araştırmada, üç farklı anaca aşılı (5BB, SO4 ve 11OR) 'Kokulu Kara Üzüm' (V. labrusca L.) ve 'Şiraz' (Vitis vinifera L.) çeliklerinin ağır killi toprak yapısına sahip fidanlık şartlarında köklenme ve fidan gelişim düzeyleri belirlenmiştir. Araştırmada anaçların kaynaştırama odası performansı, fidan randımanı ile bazı büyüme parametreleri incelenmiştir. Elde edilen veriler 'Tartılı Derecelendirme Metodu' kullanılarak değerlendirilmiştir. Değerlendirme sonucuna göre ağır bünyeli fidanlık toprağı şartlarında 5BB anacı Kokulu Kara Üzüm ve Şiraz çeşidi için en yüksek puanı almıştır.

Anahtar Kelimeler: Ağır bünyeli toprak, Aşı, Anaç, Aşılı fidan, Tartılı derecelendirme

\section{The Effects of Grafted Vine Yield and Growth of 'Foxy Grape'(Vitis labrusca L.) and Shiraz (Vitis vinifera L.) Grape on Grafted Different Rootstocks in the Heavy Textured Soil Conditions}

\begin{abstract}
Grafted vines are the only option while establishing vineyards over the sites contaminated with phylloxera. Grafted vines will be used to establishment new vineyards should be well-developed, healthy and compatible with the scions. In the grafted vines production the importance of nursery soil on the yield and quality of grafted grapevine production is too much. The purpose of this study was to determine the effect on rooting and vine vine growth of grafted cuttings of 'Foxy Grape' (Vitis labrusca L.) and 'Shiraz' (Vitis vinifera L.) grapes on three different rootstocks in the heavy clay nursery conditions. In the study, callusing room performance of the rootstock, grafted vine yield and root development and some growth parameters were investigated. The data were evaluated with using the Weighted Ranking Method. According to weighted ranking points, 5BB rootstock received the highest score for Vitis labrusca L. and Shiraz grapes in heavy textured soil conditions.
\end{abstract}

Key Words: Heavy soil textured, Grafting, Rootstocks, Grafted vine, Weighted ranking

\section{Giriş}

Filoksera ile bulaşık alanlarda bağ kurarken tek seçenek aşılı asma fidanı kullanmaktır. Bununla birlikte, yeni kurulacak bağlarda kullanılan aşılı asma fidanlarının iyi geliş̧iş, sağııkı ve anaca aşılı çeşitle uyuşur olması gerekir (Vršič ve ark., 2004). Asma 
anaçlarının, üzüm çeşitlerin gelişimi ve kalitesi üzerine farklı etkileri pek çok çalışmada ortaya konulmuştur (Cangi, 1998; Çelik, 2000; Doğan ve ark., 2000; Hamdan ve Salimia, 2010). Asma fidanı üretiminde başarıyı etkileyen pek çok faktör bulunmakta ve bunlar afiniteyi ve fidan randımanını önemli derecede etkilemektedir (Şen ve Yağcı, 2016). Asma fidanı üretimindeki kalite ve randımanı kaynaştırma odası uygulamaları ile köklendirme aşamasındaki ekolojik ve kültürel uygulamalar belirlemektedir. Asma fidanı üretiminde çeşit/anaç ilişkileri, fidan gelişimini ve fidan randımanını etkilemektedir (Kısmalı, 1978; Cangi, 1998). Fidan randımanı ve kalitesini artırmak için, anaç ve kalem arasındaki kallus bağlantısının çok iyi kurulması, kaynaşmanın çevresel ve sağlıklı olması, fidanlık şartlarının optimum düzeyde bulunması gerekmektedir (Eriş ve ark., 1989; Ecevit ve Baydar, 2000). Anaç ve üzüm çeşitlerinin değişik ekolojik koşullara adaptasyonu farklılık gösterdikleri gibi, çeşit/anaç kombinasyonlarında büyüme, gelişme, beslenme, verim, kalite, uyuşma ve adaptasyon yönünden çok çeşitli sorunlar çıkabilmektedir. Bu açıdan, herhangi bir kombinasyona karar vermeden önce kullanılan anacın çeşitle uyumu, bölge iklim ve toprak koşullarına adaptasyonu, üzerine aşılanan çeşidin büyüme, gelişme ve beslenmesine etkilerinin tam olarak ortaya konulması gerekir (Çelik ve Odabaş, 1994; 1995; Türkben ve Sivritepe, 2000).

Fidanlık kayıpları olarak bilinen ve kaynaştırılan aşılı çeliklerin köklendirme parsellerine aktarılması sırasında ve sonrasında ortaya çıkan kayıplar fidan randımanını etkilemekte bu oran ülkemizde \%30'u geçemediği bildirilmektedir. (Çelik, 1984). Aşılı asma fidanı üretiminde, fidanlık toprağının yapısı ve aşılı çeliklerin dikimini izleyen ilk 2-3 haftalık süre içindeki toprak ve iklim koşulları başarıyı büyük ölçüde etkilemektedir. Özellikle ağır toprak yapısına sahip fidancılık işletmelerinde, takip eden dönemde havanın serin ve yağışlı gitmesi ile kambiyal bağlantının sağlanması ve gelişmesini sürdüremediğinden, aşı tutma başarısı düşmektedir. Toprak yapısının çok hafif ve suyun yetersiz olduğu fidanlıklarda ise dikim sonrası havaların çok sıcak olmasının da başarıyı olumsuz yönde etkilediği belirtilmektedir (Çelik ve ark., 1992). Dolayısıyla fidanlık koşullarındaki iklim şartlarının kontrol altına alınması ve kallus oluşumu için \%85-95 oransal nemle $25{ }^{\circ} \mathrm{C}$ civarındaki sıcaklığın temin edebileceği yetiştirme sistemlerinden istifade etmek gerekmektedir (Karakır ve ark., 1988).

$\mathrm{Bu}$ araştırma, Samsun Ondokuz Mayıs Üniversitesi Ziraat Fakültesi Araştırma ve Uygulama arazisinde yürütülmüştür. Araştırmanın yürütüldüğü alan ağır killi toprak yapısına sahiptir. Vitis labrusca L. türüne giren 'Kokulu Kara Üzüm' Karadeniz Bölgesi sahil şeridinde oldukça yoğun yetiştirilmektedir. Şiraz üzüm çeşidi son derece kaliteli şaraplık bir üzüm çeşidi olup son yıllarda bu çeşide olan ilgi giderek artmaktadır. Bu amaçla aşılamada, kök yapısı ve gelişimi kuvvetli olan Kober 5BB ve $\mathrm{SO} 4$ anaçları ile nispeten daha zayıf kök yapısına sahip 110R anacı seçilmiştir. Araştırmanın amacı; ağır killi toprak yapısına sahip fidanlık şartlarında farklı anaçlara aşılı Vitis labrusca L. ve Şiraz üzüm çeşitlerine ait aşılı çeliklerin köklenme, fidan randımanı ve fidan gelişimi üzerine etkilerini belirlemek ve uygun çeşit/anaç kombinasyonunu tespit etmektir.

\section{Materyal ve Metot}

Araştırma 2014 yılında Ondokuz Mayıs Üniversitesi Ziraat Fakültesi'nde yürütülmüştür. 5BB, SO4 ve $110 \mathrm{R}$ anaçlarının bir yaşlı çelikleri Manisa Bağcılık Araştırma 
Enstitüsü'nden sağlanmıştır. Anaçlara ait çelikler ve aşı kalemleri aşı zamanına kadar +2 ${ }^{\circ} \mathrm{C}$ 'de ve \% 90-95 nem içeren soğuk hava deposunda muhafaza edilmiştir (Çelik ve Odabaş, 1999). 8-12 mm kalınlığındaki anaçlar 'Kokulu Kara Üzüm' (Vitis labrusca L.) ve 'Şiraz' (Vitis vinifera L.) üzüm çeşitlerine ait tek gözlü kalemlerle omega aşı makinasıyla aşılanmıştır. Aşılamadan önce anaç ve kalemlere fungusit uygulanmıştır. Aşılama 5 Nisan 2014 tarihinde masa başı omega aşı makinası ile yapılmıştır. Aşı bölgesi parafine batırılaraktan sonra hızlıca soğuk suya daldırılarak parafinin donması sağlanmıştır. Plastik kasalara yerleştirilen aşılı çeliklerin aralarına ince nemli talaş serpiştirildikten sonra, üzeri 2 hafta nemli gazete kâğıdı ve siyah polietilen plastik örtü ile kapatılmış, daha sonraki haftalar kasaların üzeri açılarak oluşan sürgünlerde hastalık gelişimi takip edilmiştir. Kasalar, aşı yerinde kallus oluşumu sağlanması için 30 gün nemi ve sıcaklığı kontrol edilen oda şartlarında tutulmuştur. Odanın sıcaklığı ilk üç hafta $28{ }^{\circ} \mathrm{C}$, sonraki hafta $26{ }^{\circ} \mathrm{C}$ olarak; oda nemi ise \% 80-85 arasında tutulmuştur. Kallus oluşumu tamamlandıktan sonra, aşılı çelikler 3-4 gün oda şartlarında tutularak dış ortama alışmaları sağlanmıştır. Aşılı çelikler dikimden önce, gözlerden süren sürgünler 1-2 cm kalacak biçimde kısaltılarak ikinci parafinleme işlemi yapılmıştır. Aşılı çeliklerin dikileceği masuralara malç serilmeden önce damla sulama boruları çekilmiştir. Aşılı çeliklerin dikimi, üzeri siyah malç çekilmiş $60 \mathrm{~cm}$ enindeki masuralara çift sıra dikim sistemiyle 9 Mayıs 2014 tarihinde gerçekleşmiştir. Araştırma arazisi toprağı killi, \% 4.33 organik madde ve $7.1 \mathrm{pH}^{\prime}$ ya sahiptir. Araştırma arazisinin fiziksel toprak özellikleri Çizelge 1.'de verilmiştir. Araştırma alanının sıcaklık, nispi nemi ve yağış miktarı Samsun Meteoroloji Bölge Müdürlüğü'nden sağlanmıştır (Şekil 1).

Anaçların kallus performansının değerlendirilmesi

Aşılı çeliklerde kaynaşma sonrası, aşı yerindeki kallus gelişim oranı ve kallus gelişim seviyeleri aşă̆ıdaki şekilde değerlendirilmiştir.

- Aşı yerinde kallus gelişim oranı (\%): Kallus oluşmuş aşılı çeliklerin toplam aşıı çeliklere oranı (Çelik, 2000).

- Aşı yerinde kallus gelişimi: $0=$ Kallus gelişimi olmamış, 1= \%25 kallus, 2=\%50 kallus, $3=\% 75$ kallus ve $4=\% 100$ kallus (Çelik, 2000).

\section{Aşılı Asmalarda Büyüme Parametrelerinin Ölçümü}

Asmalarda ağustos ayının ikinci haftasında toplam ve ortalama yaprak alanı $\left(\mathrm{cm}^{2}\right)$ Elsner ve Jubb (1988)'e göre; $\left[-1.41+0.527\left(\mathrm{~W}^{2}\right)+\right.$ $\left.0.254\left(L^{2}\right)\right]$ formülü ile hesaplanmıştır. Dinlenme döneminde yapraklar tamamen döküldükten sonra, fidanlar sökülerek aşağıdaki bazı büyüme parametreleri ölçülmüştür. Sökülen fidanlarda dinlenme döneminde sürgün uzunluğu $(\mathrm{cm})$, sürgün çapı $(\mathrm{mm})$, boğum arası uzunluklar $(\mathrm{cm})$, aşı yeri çapı $(\mathrm{cm})$, kök uzunluğu $(\mathrm{cm})$ ve kök gelişim seviyesi (0-4) ölçülmüştür. Asma fidanlarında fidan randımanı, kök gelişimi, aşı yeri çapı/anaç çapı aşağıdaki şekilde belirlenmiştir. 
Çizelge 1. Araştırma arazisinin fiziksel toprak özellikleri

Table 1. The physical soil properties of research area

\begin{tabular}{lccccc}
\hline $\begin{array}{c}\text { Toprak } \\
\text { Özellikleri }\end{array}$ & $\begin{array}{c}\text { pH } \\
p H\end{array}$ & $\begin{array}{c}\mathrm{EC}(\mathrm{dS} / \mathrm{m}) \\
E C(d S / m)\end{array}$ & $\begin{array}{c}\text { Organik madde (\%) } \\
\text { Organic matter }(\%)\end{array}$ & $\begin{array}{c}\mathrm{CaCO}_{3}(\%) \\
\mathrm{CaCO}_{3}(\%)\end{array}$ & $\begin{array}{c}\text { Tekstür } \\
\text { Texture }\end{array}$ \\
\hline Değerler & 7.1 & 0.62 & 4.33 & 0.85 & 62.12 \\
\hline Değerlendirme & Nötr & Tuzsuz & Yeterli & $\mathrm{Az} \mathrm{kireçli}$ & Killi \\
\hline
\end{tabular}

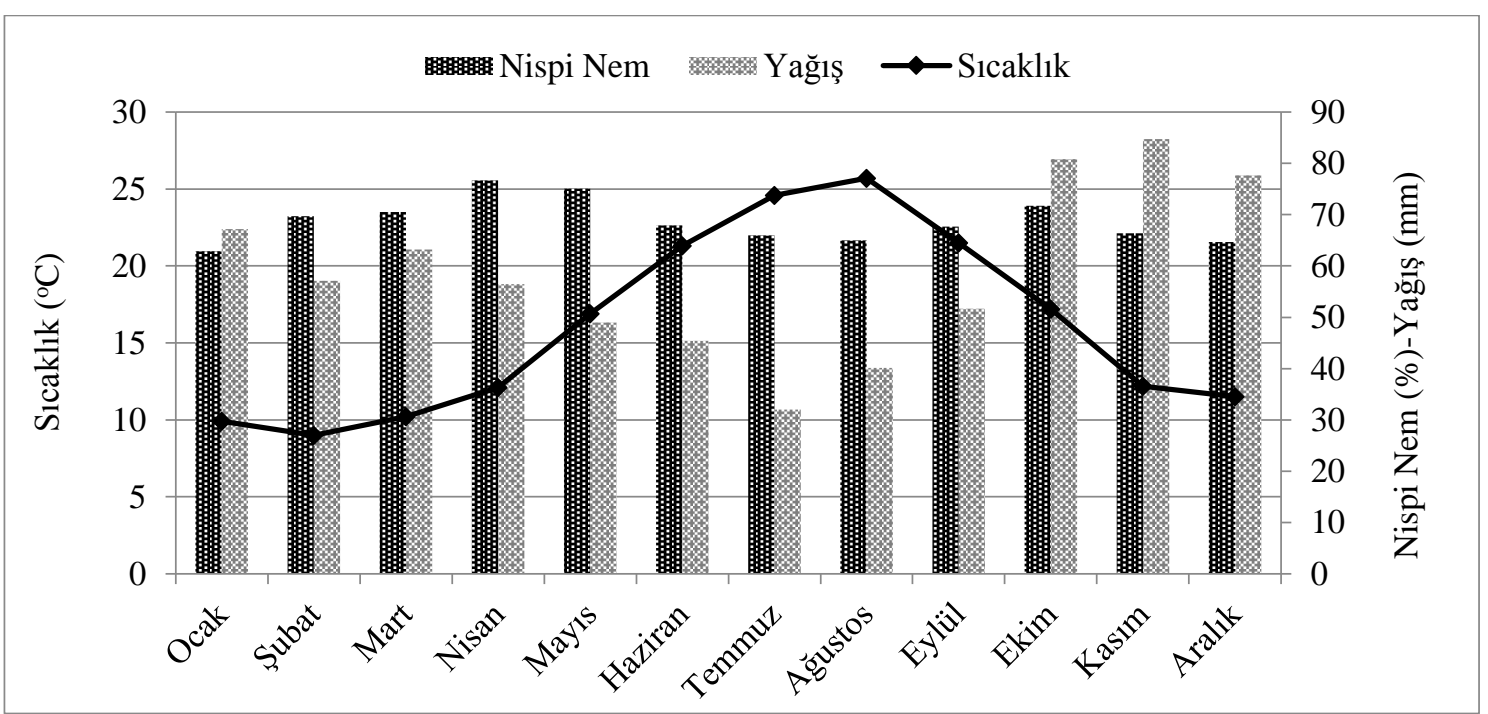

Şekil 1. 2014 yılı Samsun ili aylık ortalama sıcaklık, nispi nem ve yağış miktarı

Figure 1. The average monthly temperature, relative humidity and amounth of rainfall of Samsun province in 2014

Araştırmada, anaçların gerek aşı başarısı gerekse fidan gelişimi üzerine etkileri Köse ve ark., 2015'e göre geliştirilen modifiye tartılı derecelendirme metodu kullanılarak değerlendirilmiştir. Bu metotla her bir çeşit/anaç kombinasyonu için elde edilen toplam puan en uygun anacın tespitinde kullanılmıştır (Çizelge 2).

Araştırma, tesadüf parselleri deneme desenine göre 4 tekerrürlü olarak kurulmuştur. Aşılı çeliklerin aşı odasında kallus gelişiminin belirlenmesinde her tekerrürde her bir anaç için $50^{\prime}$ şer adet asma çeliği kullanılmıştır. Fidanlık şartlarında çeliklerin köklenme ve büyüme özelliklerinin belirlenmesinde her tekerrürde her bir anaç için 30 adet kallus gelişimi tamamlanmış aşılı çelik kullanılmıştır. Ortalamalar Duncan's multiple range test ile SPSS 16.0 programında değerlendirilmiştir. Sonuçlar ortalama ve SEM (Standart Error of Means) değerleri olarak sunulmuştur. Farklılıklar $\mathrm{P}<0.01^{\prime}$ e göre değerlendirilmiştir.

\section{Araştırma Bulguları ve Tartışma}

Aşılı çeliklerin kallus gelişim oranı (\%) ve kallus gelişim seviyesi (0-4) Çizelge 2'de verilmiştir. Anaçların kallus gelişim oranı (\%) üzerine etkileri istatistiki bakımdan önemli bulunmuştur. Kallus gelişim oranı $5 B B$ ve 110R anacına aşılı Şiraz üzüm çeşidinde daha yüksek elde edilmiştir. En yüksek kallus gelişim oranı \%92.2 ile Şiraz/5BB ve \%91.1 ile Şiraz/110R kombinasyonundan sağlanmıştır. En düşük kallus gelişim oranı ise Şiraz/SO4 kombinasyonunda \%74.4 oranı ile gerçekleşmiştir. Anaçların ve çeşit/anaç 
interaksiyonunun kallus gelişim seviyesi (0-4) üzerine etkileri istatistiki bakımdan önemli bulunmuştur. Her üç anaç içerisinde 5BB anacına aşılı $V$. labrusca ve Şiraz üzüm çeşitlerinin kallus gelişim seviyesi diğerlerine göre daha yüksek olarak tespit edilmiştir (3.82 ve 3.91). En düşük kallus gelişim seviyesi SO4 anacı üzerinde elde edilmiştir (3.72 ve 3.48). Çelik (2000), aşı yerindeki kallus gelişim seviyesinin çeşit/anaç uyuşmasının önemli bir göstergesi olduğunu belirtmiştir. Aslında pek çok araştırmacı anaçların kallus gelişim performansının anaçlara ve çeşit/anaç kombinasyonuna göre değişiklik gösterdiğini vurgulamıştır (Tangolar ve ark., 1997; Çelik ve Ağaoğlu, 1979; Ağaoğlu ve Çelik, 1982; Çoban ve Kara, 2003; Dardeniz ve Şahin, 2005; Türkben ve Sivritepe, 2000). Araştırmamızda $5 \mathrm{BB}$ anacı kallus gelişim oranı ve kallus gelişim seviyesi bakımından diğer anaçlara göre daha başarılı bulunmuştur.

Çizelge 2. Aşılı fidanların bazı büyüme özelliklerine göre tartılı derecelendirmede aldıkları puanlar

Table 2. The scores of grafted grapevines received by weighted ranking according to some growth parameters

\begin{tabular}{|c|c|c|c|}
\hline \multirow[t]{2}{*}{ Parametreler } & \multicolumn{2}{|c|}{$\begin{array}{l}\text { Sınıflandırma puanı } \\
\text { Classification points }\end{array}$} & \multirow[t]{2}{*}{$\begin{array}{c}\text { Genel Puanlama } \\
\text { General scoring }\end{array}$} \\
\hline & $\leq 50: 1$ & 71-80: 7 & \\
\hline \multirow[t]{3}{*}{ Kallus gelişim oranı (\%) } & 51-60: 3 & 81-90: 9 & 15 \\
\hline & 61-70: 5 & $\geq 91: 10$ & \\
\hline & $\leq 1,0: 1$ & $2,51-3,0: 7$ & \\
\hline \multirow[t]{3}{*}{ Kallus gelişim seviyesi (0-4) } & $1,1-2,0: 3$ & 3,01-3,5: 9 & 15 \\
\hline & 2,01-2,5: 5 & $\geq 3,51: 10$ & \\
\hline & $\leq 10: 1$ & 51-70: 7 & \\
\hline \multirow[t]{2}{*}{ Fidan randımanı (\%) } & 11-30: 3 & 71-90: 9 & 20 \\
\hline & 31-50: 5 & $\geq 91: 10$ & \\
\hline \multirow{4}{*}{ Sürgün uzunluğu (cm) } & $\leq 10 \mathrm{cm:} 1$ & $30,1-40,0 \mathrm{~cm}: 740,1-$ & \\
\hline & 10,1-20,0 cm: 3 & $50,0 \mathrm{~cm}: 9 \geq 50,1 \mathrm{~cm}:$ & 10 \\
\hline & $20,1-30,0 \mathrm{~cm}: 5$ & 10 & \\
\hline & $\leq 2,0 \mathrm{~mm}: 1$ & 5,1-7,0 mm: 7 & \\
\hline \multirow[t]{3}{*}{ Sürgün çapı (mm) } & 2,1-3,0 mm: 3 & 7,1-9,0 mm: 9 & 10 \\
\hline & 3,1-5,0 mm: 5 & $10 \geq: 10$ & \\
\hline & $\leq 1,5 \mathrm{~mm}: 10$ & $1,71-1,80 \mathrm{~mm}: 5$ & \\
\hline \multirow[t]{3}{*}{ Aşı çapı / Anaç çapı (mm) } & 1,51-1,60 mm: 9 & 1,81-1,90: 3 & 10 \\
\hline & $1,61-1,70 \mathrm{~mm}: 7$ & $\geq 1,91: 1$ & \\
\hline & $\leq 5,0 \mathrm{cm:} 1$ & $15,1-20,0 \mathrm{~cm}: 7$ & \\
\hline \multirow[t]{3}{*}{ Kök uzunluğu (cm) } & 5,1-10,0 cm: 3 & 20,1-25,0 cm: 9 & 10 \\
\hline & $10,1-15 \mathrm{~cm}: 5$ & $\geq 25,1 \mathrm{cm:} 10$ & \\
\hline & $\leq 1,0: 1$ & $2,51-3,0: 7$ & \\
\hline \multirow[t]{2}{*}{ Kök gelişim seviyesi (0-4) } & 1,1-2,0: 3 & 3,01-3,5: 9 & 10 \\
\hline & 2,01-2,5: 5 & $\geq 3,51: 10$ & \\
\hline Toplam & & & 100 \\
\hline
\end{tabular}


Anaçların fidan randımanı (\%), kök skalası $(0-4)$ ve ortalama kök uzunlukları $(\mathrm{cm})$ Çizelge 3 'te verilmiştir. Fidan randımanı üzerine anaç, çeşit ve çeşit/anaç interaksiyonu istatistiksel olarak önemli bulunmuştur. En yüksek fidan randımanı \%56.67 oranı ile Şiraz/5BB kombinasyonundan elde edilirken, bunu \%48.89 ile Şiraz/SO4 kombinasyonu izlemiştir. En düşük fidan randımanı ise $110 R$ anacına üzerinde tespit edilmiştir. Çeşitler arasında en yüksek fidan randımanı Şiraz üzüm çeşidinde gerçekleşmiştir. Araştırmada çeşit/anaç interaksiyonu önemli bulunmuş, Şiraz üzüm çeşidi aşılı anaçların fidan randımanı $V$. labrusca aşılı olanlara göre daha yüksek bulunmuştur. Nitekim pek çok araştırmacı çeşitlerin anacın köklenmesi üzerine etkisini yaptıkları araştırmalarla ortaya koymuşlardır (Çelik ve Ağaoğlu 1979; Eriş ve ark. 1989; Çoban ve Kara 2003; Alço ve ark., 2015; Tunçel ve Dardeniz, 2013). Richards (1983) farklı anaç türlerinin kök anatomisi, morfolojisi ve gelişiminin farklı olduğunu vurgulamıştır.

Fidanların kök skalası anaçlara ve çeşit/anaç interaksiyonuna göre farklılık göstermiştir. Araştırmada V. labrusca aşılı anaçların kök skalası, Şiraz aşılı anaçlardan daha yüksek bulunmuştur. Çalışmamızda, SO4 anacına aşılı fidanların kök skala değeri diğerlerine göre bir miktar daha yüksek olarak tespit edilmiştir.

Çizelge 3. Farklı anaçların kallus gelişimi oranı ve kallus gelişim seviyesi üzerine etkileri Table 3. The effect of different rootstocks on callus growth rate and callus development level

\begin{tabular}{llcc}
\hline \multirow{2}{*}{ Anaçlar } & Çeşitler & $\begin{array}{c}\text { Kallus gelişim seviyesi (0-4) } \\
\text { Callus development level (0-4) }\end{array}$ & $\begin{array}{c}\text { Kallus Gelişimi Oranı (\%) } \\
\text { Callus growth rate (\%) }\end{array}$ \\
\hline \multirow{2}{*}{$5 \mathrm{BB}$} & V. labrusca & $3.82 \mathrm{a}$ & $85.55 \mathrm{ab}$ \\
& Şiraz & $3.91 \mathrm{a}$ & $92.22 \mathrm{a}$ \\
\hline \multirow{2}{*}{ SO4 } & V. labrusca & $3.72 \mathrm{ab}$ & $84.44 \mathrm{ab}$ \\
& Şiraz & $3.48 \mathrm{~b}$ & $74.44 \mathrm{~b}$ \\
\hline \multirow{2}{*}{ 110R } & V. labrusca & $3.74 \mathrm{ab}$ & $84.44 \mathrm{ab}$ \\
& Şiraz & $3.88 \mathrm{a}$ & $91.11 \mathrm{a}$ \\
\hline SEM & & 0.029 & 2.152 \\
\hline Anaç & & $* *$ & $*$ \\
Çeşit & & $\mathrm{ns}$ & $\mathrm{ns}$ \\
Çeşit $x$ Anaç & & $*$ & $\mathrm{~ns}$ \\
$* *$ P<0.01, $\mathrm{P}<0.05, \mathrm{~ns}$ : non significant & &
\end{tabular}

Aşılı fidanların kök uzunlukları bakımından anaçlar arasında fark bulunmazken, çeşit ve çeşit/anaç interaksiyonu bakımından farklılık bulunmuştur (Çizelge 4). Bununla birlikte SO4 üzerine aşılı fidanların ortalama kök uzunlukları diğer anaçlara aşılı fidanlara göre bir miktar yüksek bulunmuştur. Araştırmamızda fidan randımanı, kök skalası ve ortalama kök uzunluğu bakımından $\mathrm{SO} 4$ anacı bir adım daha öne çıkmıştır. Araştırmada Şiraz üzüm çeşidi aşıı tüm anaçların fidan randımanı $V$. labrusca aşılı olanlara göre daha yüksek bulunması çeşidin üzerine aşılı olduğu anacın köklenmesi üzerine etkisinin olduğunu göstermektedir. Nitekim araştırmacılar pek çok çalışmada çeşidin anacın köklenmesi üzerine etkisinin bulunduğunu bildirmişlerdir (Doğan ve Aşkın, 1996; Yanmaz ve Yücel, 2002; Dardeniz ve Şahin, 2005; Dardeniz ve ark., 2005; Çoban ve Kara, 2003). Bunun yanı sıra Şengel (2005) fidanlık ve iklim şartlarının aşılı çeliklerin dikiminden sonraki 2-3 haftalık periyotta asma fidanı randımanını etkilediğini bildirmiştir. 
Aşılı fidanların vegetatif gelişmelerine ait sürgün uzunluğu, sürgün çapı, ortalama ve toplam yaprak alanı değerleri Çizelge 5 'de verilmiştir. Fidanların toplam yaprak ve ortalama alanları anaçlara göre farklılık göstermezken, çeşitlere ve çeşit/anaç interaksiyonuna göre farklılık göstermiştir. Araştırmada $110 R$ ve $5 B B$ üzerine aşıı fidanlarda toplam ve ortalama yaprak alanı en yüksek, en düşük toplam yaprak alanı ise Şiraz/SO4 kombinasyonunda elde edilmiştir $\left(289.60 \mathrm{~cm}^{2}\right)$. Ortalama yaprak alanı $V$. labrusca aşıı fidanlarda Şiraz aşılı fidanlara göre daha yüksek olarak belirlenmiştir (Çizelge 5).

Aşılı fidanların ortalama sürgün uzunluğu ve sürgün çapları anaç, çeşit ve çeşit/anaç interaksiyonuna göre farklılık göstermiştir. Ortalama sürgün uzunluğu ve sürgün çapı en yüksek V. labrusca/110R fidanlarında, en düşük sürgün uzunluğu ve sürgün çapı
Şiraz/SO4 fidanlarında tespit edilmiştir. Sağııkı bir asma fidanı en az $30-40$ cm'lik bir sürgün uzunluğuna sahip olmalıdır. Araştırmamızda $110 \mathrm{R}$ üzerine aşıı fidanların ortalama sürgün uzunlukları diğer iki anaca aşılı fidana göre daha fazla bulunmuştur. $V$. labrusca aşılı anaçların sürgünleri Şiraz aşııı anaçlardan daha uzun olarak bulunmuş, 5BB ve SO4 anaçlarına aşılı Şiraz çeşidinin sürgün uzunlukları $30 \mathrm{~cm}$ 'nin altında kalmıştır. 110R anacı kuvvetli anaçlar arasında yer aldığından aşılı fidanların kök ve sürgün uzunlukları 5BB ve SO4 aşılı olanlara göre daha fazla olmuştur. Eğer anacın kök sistemi kuvvetli ise üzerine aşılı kalemin gelişimini etkileyebilmektedir (Jogaiah ve ark. 2013). Nitekim pek çok araştırmacıya göre anaçlar üzerine aşııı çeşidin gücünü etkilemektedir (Williams ve Smith 1991, Smart ve ark., 2006; Striegler ve Howell, 1991; Tandonnet ve ark., 2010).

Çizelge 4. Farklı anaçların köklenme oranları, kök skalası ve ortalama kök uzunluğu üzerine etkileri

Table 4. The effect of different rootstocks on grafted vine yield, root length and root scale

\begin{tabular}{llccc}
\hline \multirow{2}{*}{ Anaçlar } & Çeşitler & $\begin{array}{c}\text { Fidan randımanı (\%) } \\
\text { Grafted vine ratio (\%) }\end{array}$ & $\begin{array}{c}\text { Ortalama Kök Uzunluğu (cm) } \\
\text { Mean root length (cm) }\end{array}$ & $\begin{array}{c}\text { Kök Skalası (0-4) } \\
\text { Root scale (0-4) }\end{array}$ \\
\hline \multirow{2}{*}{$5 \mathrm{BB}$} & V. labrusca & $36.67 \mathrm{~b}$ & $22.69 \mathrm{abc}$ & $2.97 \mathrm{a}$ \\
& Şiraz & $56.67 \mathrm{a}$ & $19.21 \mathrm{c}$ & $2.92 \mathrm{ab}$ \\
\hline \multirow{2}{*}{ SO4 } & V. labrusca & $35.56 \mathrm{~b}$ & $25.06 \mathrm{ab}$ & $3.16 \mathrm{a}$ \\
& Şiraz & $48.89 \mathrm{ab}$ & $20.82 \mathrm{bc}$ & $2.89 \mathrm{ab}$ \\
\hline \multirow{2}{*}{$110 \mathrm{R}$} & V. labrusca & $5.56 \mathrm{c}$ & $26.62 \mathrm{a}$ & $3.00 \mathrm{a}$ \\
& Şiraz & $16.67 \mathrm{c}$ & $18.74 \mathrm{c}$ & $2.20 \mathrm{~b}$ \\
\hline SEM & 2.152 & 0.703 & 0.103 \\
\hline Anaç & $* *$ & $\mathrm{~ns}$ & $*$ \\
Çeşit & $* *$ & $* *$ & $\mathrm{~ns}$ \\
Çeşit $\mathrm{x}$ Anaç & $* *$ & $*$ & $*$ \\
$* *$ P<0.01, ${ }^{*} \mathrm{P}<0.05$, ns: non significant & & &
\end{tabular}


Çizelge 5. Aşılı fidanlarda anaçların yaprak alanı ve sürgün gelişimi üzerine etkileri

Table 5. The effects of rootstocks on leaf area and shoot development in grafted vines

\begin{tabular}{|c|c|c|c|c|c|}
\hline Anaçlar & Çeşitler & $\begin{array}{c}\text { Toplam yap. alanı } \\
\left(\mathrm{cm}^{2}\right) \\
\text { Total leaf area } \\
\left(\mathrm{cm}^{2}\right)\end{array}$ & $\begin{array}{l}\text { Ort. yaprak alanı } \\
\left(\mathrm{cm}^{2}\right) \\
\text { Mean leaf area } \\
\left(\mathrm{cm}^{2}\right)\end{array}$ & $\begin{array}{l}\text { Sürgün çapı } \\
(\mathrm{mm}) \\
\text { Soot diameter } \\
(\mathrm{mm})\end{array}$ & $\begin{array}{c}\text { Sürgün } \\
\text { uzunluğu }(\mathrm{cm}) \\
\text { Shoot length } \\
(\mathrm{cm})\end{array}$ \\
\hline \multirow{2}{*}{$5 B B$} & V. labrusca & $524.93 a$ & $47.48 a$ & $4.25 b c$ & $37.82 b$ \\
\hline & Şiraz & 503.19ab & $32.07 \mathrm{~cd}$ & $4.36 \mathrm{bc}$ & $22.71 \mathrm{c}$ \\
\hline \multirow{2}{*}{ SO4 } & V. labrusca & $537.54 a$ & $46.01 \mathrm{ab}$ & $5.06 b$ & $40.91 b$ \\
\hline & Şiraz & $289.60 c$ & $23.33 d$ & $3.83 c$ & $22.86 \mathrm{c}$ \\
\hline \multirow{2}{*}{$110 \mathrm{R}$} & V. labrusca & 456.63ab & $47.48 \mathrm{a}$ & $6.35 a$ & $56.20 a$ \\
\hline & Şiraz & $571.05 a$ & $36.17 b c$ & $4.80 \mathrm{bc}$ & $37.97 \mathrm{~b}$ \\
\hline \multicolumn{2}{|l|}{ SEM } & 30.584 & 1.459 & 0.145 & 1.923 \\
\hline \multicolumn{2}{|l|}{ Anaç } & ns & ns & $* *$ & $* *$ \\
\hline \multicolumn{2}{|c|}{ Çeşit } & ns & $* *$ & $* *$ & $* *$ \\
\hline \multicolumn{2}{|c|}{ Çeşit $x$ Anaç } & $*$ & $* *$ & $* *$ & $* *$ \\
\hline
\end{tabular}

Aşılı fidanların aşı yeri çapı, anaç çapı ve aşı yeri/anaç çapı değerleri Çizelge $6^{\prime}$ da verilmiştir. Aşı yeri çapı, anaç çapı ve aşı yeri/anaç çapı anaçlara ve çeşitlere göre farklılık göstermezken, çeşit/anaç interaksiyonuna göre aşı yeri çapı ve anaç çapı farklılık göstermiştir (Çizelge 6). En yüksek aşı yeri çapı ve anaç çapı 110R üzerine aşılı $V$. labrusca fidanlarında elde edilirken, en düşük değerler 110R üzerine aşılı Şiraz fidanlarında tespit edilmiştir. Araştırmamızda aşılı fidanların bazı büyüme parametreleri ile kallus gelişim performansına ait veriler kullanılarak en başarılı çeşit/anaç kombinasyonu tartılı derecelendirme metodu kullanılarak belirlenmeye çalışılmıştır. Aşılı fidanların tartılı derecelendirme sonunda elde ettiği toplam puanlar Çizelge 7'de sunulmuştur. Tartılı derecelendirme sonucuna göre $V$. labrusca için en yüksek puanı $\mathrm{SO} 4$ anacı, Şiraz için ise en yüksek puanı 5BB anacı almıştır.

Çizelge 6. Anaçların anaç ve aşı bölgesi çapı üzerine etkileri

Table 6. The effect of rootstocks on rootstock and graft union diameter

\begin{tabular}{llccc}
\hline Anaçlar & Çeşitler & $\begin{array}{c}\text { Aşı yeri çapı (mm) } \\
\text { Graft union diameter }(\mathrm{mm})\end{array}$ & $\begin{array}{c}\text { Anaç çapı (mm) } \\
\text { Rootstock diameter }(\mathrm{mm})\end{array}$ & $\begin{array}{c}\text { Aşı yeri/Anaç çapı (mm) } \\
\text { Graft union / Rootstock } \\
\text { diameter (mm) }\end{array}$ \\
\hline \multirow{2}{*}{$5 \mathrm{BB}$} & V. labrusca & $10.60 \mathrm{bc}$ & $9.46 \mathrm{~b}$ & 1.13 \\
& Şiraz & $10.87 \mathrm{abc}$ & $10.20 \mathrm{ab}$ & 1.06 \\
\hline \multirow{2}{*}{ SO4 } & V. labrusca & $11.97 \mathrm{ab}$ & $10.28 \mathrm{ab}$ & 1.17 \\
& Şiraz & $10.69 \mathrm{bc}$ & $10.02 \mathrm{ab}$ & 1.07 \\
\hline \multirow{2}{*}{$110 \mathrm{R}$} & V. labrusca & $12.56 \mathrm{a}$ & $10.96 \mathrm{a}$ & 1.14 \\
& Şiraz & $10.16 \mathrm{c}$ & $9.31 \mathrm{~b}$ & 1.09 \\
\hline SEM & & 0.238 & 0.180 & 0.015 \\
\hline Anaç & Çeşit & $\mathrm{ns}$ & $\mathrm{ns}$ & $\mathrm{ns}$ \\
Çeşit $x$ Anaç & $\mathrm{ns}$ & $\mathrm{ns}$ & $\mathrm{ns}$ \\
\hline
\end{tabular}

** $\mathrm{P}<0.01,{ }^{*} \mathrm{P}<0.05$, ns: non significant 
Çizelge 7. Tartılı derecelendirmeye göre anaçların değerlendirilmesi

Table 7. The evaluation of rootstocks according to weighted ranking

\begin{tabular}{|c|c|c|c|c|c|c|c|c|c|}
\hline \multirow{3}{*}{ Anaçlar } & \multicolumn{9}{|c|}{$\begin{array}{l}\text { Anaçların Puanlaması } \\
\text { Scoring of rootstocks }\end{array}$} \\
\hline & \multirow[t]{2}{*}{ Çeşitler } & \multicolumn{2}{|c|}{$\begin{array}{l}\text { Kallus gelişim } \\
\text { oranı (\%) } \\
\text { Callus growth } \\
\text { rate (\%) }\end{array}$} & \multicolumn{2}{|c|}{$\begin{array}{c}\text { Kallus gelişim } \\
\text { seviyesi (0-4) } \\
\text { Callus } \\
\text { development } \\
\text { level (0-4) }\end{array}$} & \multicolumn{2}{|c|}{$\begin{array}{c}\text { Sürgün } \\
\text { uzunluğu }(\mathrm{cm}) \\
\text { Shoot length } \\
(\mathrm{cm})\end{array}$} & \multicolumn{2}{|c|}{$\begin{array}{l}\text { Sürgün } \\
\text { çapı (mm) } \\
\text { Shoot } \\
\text { diameter } \\
(\mathrm{mm})\end{array}$} \\
\hline & & & $S P * G P$ & SP & $S P * G P$ & SP & $\mathrm{SP} * \mathrm{GP}$ & SP & $S P * G P$ \\
\hline \multirow{2}{*}{$5 B B$} & V. labrusca & $\subseteq$ & 135 & 10 & 150 & 7 & 70 & 5 & 500 \\
\hline & Şiraz & & 150 & 10 & 150 & 5 & 50 & 5 & 50 \\
\hline \multirow{2}{*}{ SO4 } & V. labrusca & $\varsigma$ & 135 & 10 & 150 & 9 & 90 & 5 & 50 \\
\hline & Şiraz & 7 & 105 & 9 & 135 & 5 & 50 & 5 & 50 \\
\hline \multirow{2}{*}{$110 \mathrm{R}$} & V. labrusca & $\varsigma$ & 135 & 10 & 150 & 10 & 100 & 7 & 70 \\
\hline & Şiraz & & 150 & 10 & 150 & 7 & 70 & 5 & 50 \\
\hline \multirow[t]{2}{*}{ Anaçlar } & Çeşitler & \multicolumn{2}{|c|}{$\begin{array}{c}\text { Kök gelişim } \\
\text { seviyesi (0-4) } \\
\text { Root } \\
\text { development } \\
\text { level (0-4) }\end{array}$} & \multicolumn{2}{|c|}{$\begin{array}{l}\text { Kök uzunluğu } \\
\text { (cm) } \\
\text { Root length } \\
\text { (cm) }\end{array}$} & \multicolumn{2}{|c|}{$\begin{array}{c}\text { Fidan } \\
\text { randımanı (\%) } \\
\text { Grafted vine } \\
\text { efficiency (\%) }\end{array}$} & \multicolumn{2}{|c|}{$\begin{array}{l}\text { Aşı yeri/Anaç } \\
\text { çapı (mm) } \\
\text { Graft union / } \\
\text { Rootstock } \\
\text { diameter } \\
(\mathrm{mm})\end{array}$} \\
\hline & & SP & SP*GP & SP & $\mathrm{SP} * \mathrm{GP}$ & $\mathrm{S}$ & $S P * G P$ & SP & $\mathrm{SP} * \mathrm{G}$ \\
\hline \multirow{2}{*}{$5 \mathrm{BB}$} & V. labrusca & 7 & 70 & 9 & 90 & 5 & 100 & 10 & 100 \\
\hline & Şiraz & 7 & 70 & 7 & 70 & 7 & 140 & 10 & 100 \\
\hline \multirow{2}{*}{ SO4 } & V. labrusca & 9 & 90 & 10 & 100 & 5 & 100 & 10 & 100 \\
\hline & Şiraz & 7 & 70 & 9 & 90 & 5 & 100 & 10 & 100 \\
\hline \multirow{2}{*}{$110 \mathrm{R}$} & V. labrusca & 7 & 70 & 10 & 100 & 1 & 10 & 10 & 100 \\
\hline & Şiraz & 5 & 50 & 7 & 70 & 3 & 30 & 10 & 100 \\
\hline & \multicolumn{9}{|c|}{$\begin{array}{l}\text { Anaç puanı } \\
\text { Rootstock score }\end{array}$} \\
\hline \multicolumn{3}{|c|}{$5 B B$} & \multicolumn{3}{|c|}{ SO4 } & \multicolumn{4}{|c|}{ 110R } \\
\hline \multicolumn{2}{|l|}{ V. labrusca } & Şiraz & V. labrusca & & Şiraz & \multicolumn{2}{|c|}{ V. labrusca } & \multicolumn{2}{|c|}{ Şiraz } \\
\hline 765 & \multicolumn{2}{|c|}{780} & 815 & \multirow{2}{*}{\multicolumn{2}{|c|}{757}} & & 745 & & 700 \\
\hline & 772 & & & & & \multicolumn{4}{|c|}{722} \\
\hline
\end{tabular}

SP: Sınıflandırma Puanı. Genel Puan: GP.

\section{Sonuçlar}

Bu araştırmada, 5BB, SO4 ve 110R anaçlarına aşılı V. labrusca ve Şiraz çeşidinin aşı odası performansı yanı sıra, ağır killi toprak yapısına sahip fidanlık koşullarında bunların aşılı çeliklerinin köklenme ve büyüme parametreleri tartılı derecelendirme metodu kullanılarak değerlendirilmiştir. Elde edilen değerlerin tartılı derecelendirilmesi sonucunda $V$. labrusca için en yüksek puanı SO4 anacı, Şiraz çeşidi için ise 5BB anacı almıştır. Ortalama puan bakımından değerlendirildiğinde ise 5BB anacı en yüksek puanı alarak ağır bünyeli fidanlık toprağı şartlarında incelenen parametreler bakımından en başarılı anaç olmuştur

Ekler

$\mathrm{Bu}$ araştırmada kullanılan anaçların temininde katkılarından dolayı Manisa Bağcılık Araştırma Enstitüsü'ne teşekkür ederiz. 


\section{Kaynaklar}

Ağaoğlu, Y.S., Çelik, H., 1982. Effect of grafting machines on success of grafted vine production. Uludağ Üniversitesi Ziraat Fakültesi Dergisi, 1: 25-32, Bursa.

Alço, T., Dardeniz, A., Sağlam, M., Özer, C., Açikbaş, B., 2015. Aşılı asma fidanı üretiminde farklı çeşit/anaç kombinasyonlarının aşı odası randımanı ile kallus gelişim düzeyi üzerine etkileri. Selçuk Tarım ve Gıda Bilimleri Dergisi, Cilt A-27, s8-16.

Cangi, R., 1998. Asma fidanı gelişimine anaçların etkileri üzerine bir araştırma. 4. Bağcılık Sempozyumu, Yalova, s 412-416.

Çelik, H., Ağaoğlu, Y.S., 1979. Aşılı köklü asma fidanı üretiminde farklı çeşit/anaç kombinasyonlarının aşıda başarı üzerine etkileri. Ankara Üniv. Ziraat Fakültesi Yıllığı, 79:222-232.

Çelik, H., 1984. Türkiye Bağcılığında Fidan Sorunu. Tokat Bağcılığı Sempozyumu, 25-28 Ekim 1984, Tokat. Tekel İşl. Gn. Müdürlüğü, Cumhuriyet Üniversitesi Tokat Ziraat Fakültesi, Tokat.

Çelik, S., Delice, A., Arın, L., 1992. Fidanlık kosullarında asılı asma fidanı üretimi. DOĞA, Turkish Journal of Agriculture and Forestry, 16: 507-518.

Çelik, H., 2000. The effects of different grafting methods applied by manual grafting units on grafting success in grapevines. Turkish Journal of Agriculture and Forestry, 24: 499-504.

Çelik, H., Odabaş, F., 1994. Bağcılıkta uyuşma ve afinite. Hasat Dergisi, (Ocak): 37-41.

Çelik, H., Odabaş, F., 1995. Farklı anaçlar üzerine aşılanan bazı üzüm üzerinde aşı tipi ve aşılama zamanlarının fidanların büyüme ve gelişmeleri üzerine etkileri. Türkiye II. Bahçe Bit.Kong. Cilt II, Adana, s. 464-468.

Çelik, H., Odabaş, F., 1999. Fidanlık koşullarında aşılı asma fidanı üretiminde aşı tipi ve aşılama zamanlarının fidan kalitesi üzerine etkileri, Turkish Journal of Agriculture and Forestry, 23: 87-95.

Çoban, H., Kara, S., 2003. Bazı üzüm (Vitis vinifera L.) çeşitlerinin asma anaçları ile aşı tutma durumu ve fidan kalitesine etkileri üzerine araştırmalar. Anadolu Ege Tarımsal Araştırmalar Enstitüsü Dergisi, 13: 176187.
Dardeniz, A., Kısmalı, İ., Şahin, A.O., 2005. Bazı sofralık üzüm çeşitlerinin aşılı fidan randımanları ile fidanlıktaki vejetatif gelişmelerinin belirlenmesi. Türkiye 6 . Bağcılık Sempozyumu, Cilt: 2, 498-505,1923 Eylül, Tekirdağ.

Dardeniz, A., Şahin, A.O., 2005. Aşılı asma fidanı üretiminde farklı çeşit ve anaç kombinasyonlarının vejetatif gelişme ve fidan randımanı üzerine etkileri. Tarım ve Köy İşleri Bakanlığı, Atatürk Bahçe Kültürleri Merkez Araştırma Enstitüsü Müdürlüğü Dergisi, Bahçe, 43: 1-9.

Doğan, A., Aşkın, M.A., 1996. Aşılı Asma Fidanı Üretiminde IBA (Indol Butirik Asit) NAA (Naftalen Asetik Asit) ve Plastik Malç Uygulamalarının Fidan Randıman ve Kalitesine Etkileri Üzerine Bir Araştırma. Yüzüncü Yıl Üniversitesi, Fen Bilimleri Enstitüsü, Bahçe Bitkileri Anabilim Dalı, Doktora Tezi, Van.

Doğan, A., Cangi, R., Yarılgaç, T., 2000. Aşılı Asma Fidanı Üretiminde Aşı Kalemine IBA Uygulamasının Kallus Oluşumu ve Aşı Kaynaşmasının Gelişimi Üzerine Etkileri. II. Ulusal Fidancılık Sempozyumu, 25-29 Eylül, 2000.

Ecevit, F., Baydar, N., 2000. Aşılı asma fidanı üretiminde farklı aşılama yöntemlerinin aşıda başarı üzerine etkileri. II. Ulusal Fidancılık Sempozyumu, Ödemiş, s21.

Elsner, E.A., Jubb, G.L., 1988. Leaf Area Estimation of Concord Grape Leaves from Simple Linear Measurements. American Journal of Enology and Viticulture, 39: 95-97.

Eriş, A., Soylu, A., Türkben, C., 1989. Aşlı köklü asma fidanı üretiminde bazı uygulamaların aşı yerinde kallus oluşumu ve köklenme üzerine etkileri. Bahçe, 18: 29-34.

Hamdan, A.J.S., Salimia, R.B., 2010. Preliminary Compatibility between some tablegrapevine scion and phylloxera-resistant rootstock cultivars. Jordan Journal of Agricultural Sciences, 6: 1-9.

Jogaiah, S., Oulkar, D.P., Vijapure, A.N., Maske, S.R., Sharma, A.K., Somkuwar, R.G., 2013. Influence of canopy management practices on fruit composition of wine grape cultivars grown in semiarid tropical region of India. African Journal of Agricultural Research, 8: 3462-3472.

Karakır, M.N., Uzun, H.I., İlter, E., 1988. 5BB 99R anaçlarına aşılı yuvarlak çekirdeksiz üzüm çeşidinde aşı başarısı, köklenme ve aşı yerini anatomik incelenmesi Türkiye 
Üçüncü Bağcılık Sempozyumu, s88-92, Bursa.

Kısmalı, İ., 1978. Yuvarlak Çekirdeksiz üzüm çeşidi ve farklı amerikan asma anaçları ile yapılan aşılı-köklü asma fidanı üretimi üzerinde araştırmalar. Ege Üniversitesi Ziraat Fakültesi Meyve ve Bağ Yetiştirme ve Islahı Kürsüsü. Doçentlik Tezi, s102, Bornovaİzmir.

Köse, B., Çelik, H., Karabulut, B., 2015. Determination of callusing performance and vine vine characteristics on different rootstocks of 'Merzifon Karasi' grape variety (Vitis vinifera L.). Anadolu Tarim Bilimleri Dergisi, 30: 87-94.

Richards, D., 1983. The grape root system. Horticultural Reviews, 5:127-168.

Şen, A.B., Yağcı, A., 2016. Tüplü Asma Fidanı Üretiminde Farklı Köklendirme Yerlerinin Fidan Randıman ve Kalitesi Üzerine Etkileri. Meyve Bilimi, 3: 22-28.

Şengel, E., 2005. A Research on the effects of three different rooting material on the quality and yield on tubed grape graft production under the conditions of hydrophonic culture methods. Ege University Science Institute, Master's thesis, $87 \mathrm{p}$, (Unpublished), (Turkish).

Smart, D.R., Schwass, E., Lakso, A., Morano, L., 2006. Grapevine rooting patterns: a comprehensive analysis and a review. American Journal of Enology and Viticulture, 57: 89-104.

Striegler, R.K., Howell, G.S., 1991. The influence of rootstock on the cold hardiness of Seyval grapevines. I. Primary and secondary effects on growth, canopy development, yield, fruit quality and cold hardiness. Vitis 30: 1-10.

Tandonnet, J.P., Cookson, S.J., Vivin, P., Ollat, N., 2010. Scion genotype controls biomass allocation and root development in grafted grapevine. Australian Journal of Grape and Wine Research 16: 290-300.

Tangolar, S., Ergenoglu, F., Gök, S., Kamiloğlu, Ö., 1997. Research on determination of on Temperate Zone Fruits, Ed. A.B. Küden, F.G. Dennis, Acta Horticulturae, 441: 399401. Fifth International Symposium on TZFTS, May 29-June 1, 1996, Adana, Turkey.

Tunçel, R., Dardeniz, A., 2013. Aşılı asma çeliklerinin fidanlıktaki vejetatif gelişimi ve randımanları üzerine katlamanın etkileri.
TABAD Tarım Bilimleri Araştırma Dergisi, Tarım Sempozyumu Özel Sayısı (Prof. Dr. Selahattin İptaş anısına), 6 (1): 118-122.

Türkben, C., Sivritepe, N., 2000. Aşılı köklü asma fidanı üretiminde bazı dışsal uygulamaların aşı yerinde kallus oluşumu ve kökleşme üzerine etkileri. II. Ulusal Fidancılık Sempozyumu Ödemiş, s29.

Vršič, S., Valdhuber, J., Pulko, B., 2004. Compatibility of the rootstock Börner with various scion varieties. Vitis, 43: 155-156.

Williams, L.E., Smith, R.J., 1991. The effect of rootstock on the portioning of dry weight, nitrogen and potassium, and root distribution of Cabernet Sauvignon grapevines. American Journal for Enology and Viticulture, 4:118-122.

Yanmaz, M., Yücel, A., 2002. 110R Amerikan Asma Anacına Değişik Üzüm Çeşitlerinin Aşılanması Üzerine Bir Araştırma. Harran Üniversitesi, Fen Bilimleri Enstitüsü, Bahçe Bitkileri Anabilim Dalı, Yüksek Lisans TeziŞanlıurfa. 